\title{
Différance e Comunicação
}

\section{Flávio Vinicius Cauduro}

PhD em Comunicação Gráfica, University of Reading, UK Prof. do Programa de Pós-graduação da FAMECOS / PUCRS
SEGUNDO A SEMIÓTICA PÓS-ESTRUTURALISTA, um signo, uma forma, um texto, não podem mais continuar sendo considerados como simples veículos ou receptáculos para o transporte e propagação de um conteúdo, sentido, ou significado único, fixo, prédeterminado; porque sinais materiais só "contêm" a si mesmo, passando a produzir sentido ou significado somente quando interpretados, isto é, só depois de conectados com outros sinais, presentes no texto (in prae-sentia) e/ou na memória do sujeito inter-pretante (textos in absentia). Portanto, o que sempre nos surge pela frente são marcas sem significação e que só passam a ter sentido quando e se as interpretarmos. Logo, signos não podem ser enviados, mas apenas recebidos (Harland 1987: 132). É a nossa leitura/escrita que transforma qualquer troca ou comunicação de sinais em signos.

Signos são pós-efeitos, produtos provisionais de processos interpretativos, conscientes e inconscientes. Seus significados são sempre passíveis de mudança e suas conotações são inesgotáveis e ilimitadas. A produtividade do significante é constante, porque o sujeito interpretante está sempre, ele mesmo, em constante mudança, en procès (em movimento/em julgamento) como afirma Kristeva, por estar/ser continuamente sujeito à prática da significação.

Se por um lado os efeitos da différance de Derrida parecem explicar satisfatoriamente diferenças de interpretação e a instabilidade e deslizamento do sentido, por outro lado não explicam como a comunicação intersubjetiva pode chegar a ocorrer de todo, sujeita que está a tantas diferenças, desencontros e mudanças. Como é que, por exemplo, os leitores de Derrida são capazes de entender, compartilhar e utilizar certas noções, certos significados, e certas estratégias da desconstrução, se a diferença é inevitável? Será que toda e qualquer comunicação é sempre uma ilusão, uma impossibilidade? Porque mesmo se cada um de seus 
leitores, intérpretes, estiver apenas disseminando seu/sua versão particular das teorias de Derrida, uma certa dose de consenso é sempre necessária para que haja um mínimo de possibilidade de comunicação, isto é, de diálogo. E isso existe.

Como poderíamos explicar a existência e permanência das instituições sociais e a reprodução de práticas sociais, se não pelo compartilhamento de sentidos e crenças entre os sujeitos? O que será que está faltando na teoria da différance?

Como outros pós-estruturalistas têm chamado a atenção de seus leitores, seguindo os mesmos pressupostos Lacanianos que informam a teoria da différance de Derrida, existem sempre clausuras ideológicas, hábitos socialmente adquiridos de pensar, assim como posições de significação que se contrapõem à disseminação e ao livre jogo do sentido - forças pré-conscientes e inconscientes que controlam e dirigem o escorregamento do significado e o fixam em certas posições preferenciais (os points de capiton de Lacan). Sem tais clausuras (closures) ideológicas, a comunicação social seria impossível.

Essas limitações, contudo, não são levadas em conta pelas teorias de Derrida, que parecem sugerir que significantes podem ter uma existência puramente subjetiva e dissociada do contexto social. Seu sujeito semiótico parece ser um ente isolado, submetido ao logocentrismo mas não constrangido por determinantes históricos, socioculturais, políticos e sexuais em geral.

Derrida enfatiza apenas o lado instável, desconstrutivo, indeciso da significação. Se por um lado a desconstrução libera o sujeito da condição de ser um suporte passivo de definições axiomáticas impostas 'de cima' por autorizados experts, por apontar para os inevitáveis paradoxos e ambigüidades que ocorrem em qualquer interpretação, por outro lado ela esquece de mencionar que tais conflitos surgem em virtude de contradições que residem na mente do sujeito predicante. E essas contradições resultam de condições externas ao sujeito, de construções socioculturais complexas, heterogêneas, divergentes mas interdependentes, e geralmente baseadas em posições históricas antagônicas, que sua memória registra e ativa posteriormente, de maneira seletiva, parcial e imprevisível.

Por outro lado, como lembra Raymond Williams (1983):

Cláudia Rodrigues

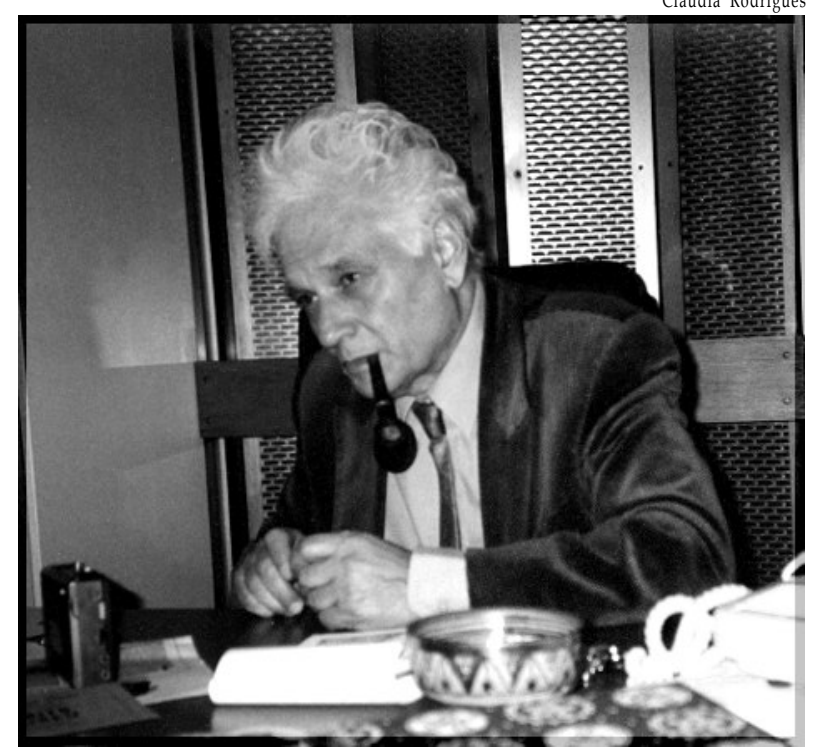

Derrida: différance e o paradoxo da comunicação.
"Na controvérsia sobre comunicação e teoria da comunicação, é útil muitas vezes relembrar o campo de abrangência não resolvido do nome original da ação, representado em seus extremos por transmitir, um processo de mão única, e compartilhar (cf. 'comunhão' e especialmente 'comunicante'), um processo comum ou mútuo. Os sentidos intermediários - tornar comum para muitos, e divulgar - podem ser lidos em qualquer uma das duas direções, e a escolha é muitas vezes crucial. Disso resulta a tentativa de generalizar a distinção em expressões contrastantes como 'comunicação(ões) manipulativa(s)' e 'comunicação(ões) participativa(s)'." (Williams 1983: 72-73, ênfases minhas)

David Sless (1986b), um professor australiano que gosta de refletir sobre a prática semiótica do design, faz referência ao trecho acima de Williams, utilizando-o como 
ponto de partida para desenvolver sua própria versão desconstrucionista da comunicação. Segundo Sless, devemos considerar a comunicação como sendo, mais que qualquer outra coisa, um ato de fé, no qual estamos permanentemente engajados para poder sobreviver:

‘O ponto principal que eu gostaria de salientar é que compartilhar, que se costuma geralmente assumir como sendo uma característica necessária e definidora da comunicação, pode não sê-lo. Não existe um conjunto de condições universalmente aceitas que possam assegurar que a relação entre emissor e receptor na comunicação envolverá compartilhamento.

....Em outras palavras, não devemos aceitar como inquestionável a idéia que comunicação envolve compartilhamento; ao contrário, devemos sempre perguntar, em qualquer instância, se o compartilhar está realmente ocorrendo.

...A idéia sobre compartilhar é um aspecto importante de nossa ideologia; ...Acreditamos no compartilhar porque sem ele o próprio tecido da vida social fica ameaçado. Quando definimos comunicação como um processo de compartilhamento não estamos descrevendo como as coisas são, mas sim como gostaríamos que elas fossem. É por essa razão que a noção de comunicação como compartilhamento permanece tendo valor para nós a despeito de argumentos e evidências [em contrário].' (Sless 1986b: 29-30)

Esta problemática muitas vezes se apresenta sob o enfoque verdade vs. mentira. Eco (1976:7), por exemplo, afirma que 'mentiras' são intrínsecas a qualquer fenômeno semiótico. Mas quantas vezes uma 'mentira' não é simplesmente uma versão da realidade diferente da nossa? E quem pode afirmar ser possível ter acesso à verdade, à objetividade, à imparcialidade, para poder distinguir, preto no branco, sem hesitar, o que é 'falso' do que é 'verdadeiro'? Essa possibilidade parece só existir para fanáticos e dogmáticos, para aqueles incapazes de aceitar o relativismo e a pluralidade.

Lembremos, a propósito, o que escreveu Edward Said (1987):

'... o que precisa ficar claro acerca do discurso cultural e do intercâmbio em uma cultura [é] que o que é costumeiramente circulado por ele não é 'a verdade' mas representações' (Said 1978: 21, ênfase minha):

'O que se deve observar [em qualquer representação] são estilo, figuras de linguagem, cenário, elementos narrativos, circunstâncias históricas e sociais, e não a exatidão da representação ou sua fidelidade a um grande original [a 'verdade'].' (Said 1978:21)

Para Sless, a possibilidade de distinção entre falso e verdadeiro também não existe. $\mathrm{O}$ que existe para ele são posições plurais de significação, e nenhuma delas deveria ser considerada mais privilegiada que as demais, na pesquisa semiótica. Por isso, ele afirma que compartilhamento não é, nem pode ser, uma característica intrínseca da comunicação, assim como também não pode ser uma de suas conseqüências inevitáveis. Se a comunicação não pode se apoiar numa crença no compartilhamento, então, como ele nota, o que parece acontecer em realidade é que, naquele processo tanto o emissor como o receptor projetam uma imagem de seus respectivos interlocutores, dos seus outros, ao construir ou ler um texto falado, escrito, etc. Essas imagens são idealizadas, afirma ele, e é em relação a esses seres hipotéticos que estruturamos nossas mensagens. Mais que isso: 'Nós imaginamos os leitores e autores projetados de forma que se ajustem aos nossos propósitos ideológicos' (Sless 1986b: 67). 
A partir dessa hipótese, Sless articula o que ele chama de uma lógica de posições, para mostrar que o sentido de um texto vai variar de acordo com a posição de seus leitores; que pesquisadores da comunicação estão sempre lendo/escrevendo seus textos 'científicos' de uma determinada posição que não podemos considerar nunca como sendo mais verdadeira ou objetiva que as demais, pois não existem posições de observação e predicação 'não-envolvidas', 'de fora', em relação aos fenômenos que analisam; que a crença no compartilhamento é uma estratégia conveniente para que analistas de discursos possam reafirmar sua autoridade sobre os textos que interpretam, o que também ocasiona a supressão de importantes considerações sobre os determinantes materiais que participam daquelas produções analisadas; e que todos nós somos cúmplices no controle e na fixação de significados de abrangência social.

Seguindo o curso das idéias de Derrida, que considera óbvias por demais, Sless rejeita algumas noções logocêntricas que são subjacentes às conceituações usuais sobre comunicação que ainda prevalecem nas sociedades ocidentais, de acordo com as quais nós deveríamos acreditar que:

'1. O texto é a expressão da intenção de um autor e portanto seu sentido não pode mudar.

2. Um texto é uma expressão da cultura na qual foi produzido e portanto seu sentido não pode mudar.

3. $\mathrm{O}$ texto se refere a verdades eternas que se aplicam a todas as pessoas em todos os tempos e portanto seu sentido não muda.

4. O texto é estruturado em um código ou linguagem que todos os membros de uma sociedade em particular compartilham e portanto seu sentido é constante dentro daquela sociedade.

5. Eu entendo o sentido deste texto e, como todos os demais são como eu próprio, o seu sentido é constante.

6. Eu sou a autoridade sobre o sentido deste texto, portanto ele deve ser lido como eu prescrevo e assim sendo o seu sentido é constante.' (Sless 1986b: 99)

Aparentemente, essas noções deveriam ter sido superadas há muito nas sociedades democráticas. Mas isso não acontece, bastando observar as disputas que se travam continuamente nos meios acadêmicos, científicos, jurídicos, políticos, jornalísticos, desportivos, religiosos, etc. sobre significados de 'textos' tais como falas, escritos, obras artísticas, experimentos, ações, atitudes, comportamentos, manifestações, fenômenos, avaliações, etc. Os profissionais da interpretação costumam ser, geralmente, os sujeitos mais inflexíveis e dogmáticos quanto à produção de sentidos não-convencionais.

Mas, como salienta Sless, mesmo tomando uma posição de resistência em relação àquelas noções autoritárias, os autores/leitores não podem fazer o que quiserem de qualquer texto, porque a escritural leitura não é um assunto de ordem estritamente pessoal (Sless 1986b: 73). Basta lembrar aqui, por exemplo, o que aconteceu com o escritor Salmon Rushdi, um desconstrucionista confesso, quando resolveu fazer uma releitura artística, uma interpretação pessoal, dos sonhos do profeta (The Satanic Verses).

Sless utiliza a palavra ideologia (no singular) diversas vezes em seu livro (In search of Semiotics), insinuando que ela é um fator de constrangimento que temos de encarar quando tentamos divergir de interpretações consolidadas de qualquer texto (o senso comum, o bom senso, a palavra oficial, a tradição, por exemplo). Mas ele não se aprofunda no tema.

Por isso, e por ele parecer supor que o sujeito semiótico está sempre totalmente consciente de seus atos, a abordagem semiótica da comunicação de Sless é demasiado racionalista e lógica, o que lhe impede de levar também em conta outras implicações importantes que o conceito de posicio- 
nalidade implica, sob os enfoques psicanalítico e feminista.

Sless deixa de lado, por exemplo, na sua teoria deconstrucionista da comunicação, o papel que o sistema inconsciente/ pré-consciente desempenha na construção e estímulo, entre outros, da diferença sexual, da clausura ou bitolamento ideológico, de ambigüidades e paradoxos, assim como de transgressões poéticas e retóricas, da criatividade, etc. Sless, em suma, ignora a comunicação como uma prática de significação governada, mais que tudo, por posicionamentos ideológicos conflitantes do sujeito, dos quais ele raramente se dá conta, e que não pode ser resolvida ou explicada em nível meramente pessoal e consciente.

Seu modelo da lógica de posições dá conta, logicamente, das divergências de interpretação e das oportunidades de reformulação do real pelo sujeito, reafirmando assim a singularidade do 'indivíduo' (aquele que não é dividido) e a capacidade do indivíduo de produzir 'suas próprias' interpretações, pressupondo que o sujeito esteja livre e desimpedido para fazer o que quiser ao acaso, seguindo seus caprichos momentâneos, sem levar em conta regras, convenções, normas e práticas de ordem sociocultural, econômica, política, sexual, etc., que, juntamente com limitações e possibilidades biológicas, determinam em última análise suas emoções, ações e pensamentos.

Por mais desconstrucionistas que queiramos ser em nossa vida diária, a maior parte de nossas emoções, ações e pensamentos cotidianos são habituais, isto é, repetitivos, e muito pouco originais dentro do contexto social em que existimos.

Como escreveu Peirce, 'três elementos estão ativos no mundo: primeiro, chance; segundo, lei; e terceiro, tomar hábito' (Peirce 1940/1955: 359). Mais ainda: 'Olhamos para trás em direção a um ponto no infinitamente distante passado quando não existia a lei, mas simplesmente indeterminação; olhamos em direção a um ponto no infinitamente distante futuro quando não haverá nenhuma indeterminação ou chance mas um reino completo da lei. Porém a qualquer data assinalável no passado, não importa quão remota, já existia alguma tendência à uniformidade; e a qualquer data assinalável no futuro existirá alguma leve aberração da lei....[Portanto, existe uma tendência no mundo de] fortalecer hábitos em leis absolutas regulando a ação de todas as coisas em todos os aspectos no futuro indefinido' (Peirce 1940/1955: 358-359).

Ou seja, estamos constantemente submetidos a uma tendência à unidade na variedade, que afeta a tudo e a todos, devido à evolução, que para Peirce nada mais é do que crescimento (Peirce 1940/1955: 357). O crescimento produz diferenças em quantidades cada vez maiores, mas, paradoxalmente, essas diferenças são cada vez mais organizadas. A oposição entre o caos e a espontaneidade total no passado e a ordem absoluta ideal no futuro é resolvida no presente atual pela tendência de todas as coisas de se diversificarem organizadamente.

Segundo Peirce, o resultado final daquela equação triádica é uma heterogeneidade organizada, ou ainda, uma variedade racionalizada (Peirce 1940/1955: 360). O que parece ser uma descrição adequada da realidade que vivemos. Se tudo foi caos, e tudo será ordem, atualmente tudo é tendência a uniformidades continuamente diversificadas. Entre a indeterminação e imprevisibilidade total, que prevaleciam por ocasião do nascimento do sujeito, e a certeza absoluta de ordem e conformidade total do sujeito por ocasião de sua morte, existe sempre um processo de vida regido por hábitos e tendências cada vez mais uniformes e duradouros, porém em número cada vez maior. As opiniões, as preferências, as possibilidades de significação abertas ao sujeito, enfim, tendem a crescer quantitativamente, mas em termos qualitativos são cada vez mais organizadas, previsíveis.

J. Buchler (em Peirce 1940/1955: ixxvi) diz que Peirce construiu um empiricismo original, no qual o falibilismo, baseado no pensamento lógico, inferencial, subs- 
titui o ceticismo Kantiano, ao mesmo tempo que o pragmatismo substitui o positivismo Comtiano, de maneira a resolver a oposição entre o acaso e as leis pela intervenção da tendência à regularidade no mundo, enquanto que seu método ou filosofia científica, da verificação experimental, representou a antítese do individualismo, do livre-arbítrio, do subjetivismo.

Assim, para Peirce, toda e qualquer conclusão ou interpretação a que chegamos é, ou deveria ser considerada, provisória e passível de correção, de maneira que não podemos estar absolutamente certos de nada nem prever com exatidão o exato valor de qualquer medida ou proporção (Peirce 1940/1955: 58). Mas, em compensação, podemos ter uma boa idéia da tendência das coisas, inclusive do que pensam nossos semelhantes. Pois para ele, todo o pensar procede como um diálogo, como um processo de comunicação interna, baseado em signos, dos quais os de mais alta ordem e validade são os símbolos (que evoluem do estado inicial de ícones para o intermediário de índices e finalmente para o final de sinais convencionais, habituais).

Segundo Peirce, um símbolo 'incorpora um hábito....e...conhecimento é hábito' (Peirce 1931: IV, 414). Ou seja, Peirce assume que com o passar do tempo, em virtude de freqüentes repetições, qualquer leitura icônica (baseada em sensações subjetivas) tende a ser indicial (passível de identificação e verificação através de sinais ou indicações factuais, concretos) para, então, tornar-se generalizável, habitual, genérica, replicável, aceita e compartilhada simbólicamente por um grupo ou comunidade.

Isto é, se uma interpretação subjetiva qualquer for adequadamente promovida, em larga escala e repetidamente pela mídia, ela se aloja na mente coletiva. Escritas e leituras icônicas e indiciais, concretas (baseadas em sensações emotivas e fatos circunstanciais), pela freqüente repetição, tendem a tornar-se escritas e leituras de domínio geral, fatos com aparência de verdades absolutas compartilhadas, que explicam crenças e hábitos estereotipados e que determinam comportamentos convencionais. Isto impede usualmente o aparecimento e a promoção de interpretações novas, originais e inovadoras.

Mas, ao mesmo tempo, não existiria comunicação sem tais estereotipações e conformidades. A repetição, a redundância, a convencionalização suportam e possibilitam a comunicação. Por outro lado, paradoxalmente, a tendência à diversificação estimula o aparecimento, o crescimento do número de canais e meios de comunicação disponíveis, o que incentiva o surgimento de interpretações e significações diferenciadas da realidade por grupos sociais minoritários e com interesses desviantes. Assim, a maior parte de nossos pensamentos e ações diários são determinados por hábitos, de leitura, escrita, comportamento e ação, ou seja, por ideologemas (Kristeva 1977/1980: 36-59), fragmentos de ideologias de vários grupos sociais, principalmente daqueles com os quais convivemos mais intensamente. Assim, nossas mentes se tornam colchas de retalhos: somos distintos uns dos outros, na totalidade, mas bastante uniformes topicamente; a nossa totalidade é imprevisível, mas seus elementos constitutivos geralmente não o são.

Peirce acreditava que cada idéia ou pensamento, cada ação ou comportamento nosso, são interpretados finalmente por algum hábito. Hábitos seriam os interpretantes finais de nossas emoções, intenções, associações e reações iniciais, nossos 'guias para a ação'. E nossas idéias seriam expressas concretamente e consistentemente através de nossos modos habituais de conduta (Urmson \& Rée 1989: 229).

Mas, como também observou Peirce,

'Hábitos diferem de disposições por terem sido adquiridos em conseqüência do princípio...de que comportamento multiplamente reiterado da mesma espécie, sob combinações similares de percepções e fantasias, produz uma tendência - o hábito - de [o 
sujeito] realmente comportar-se de maneira similar sob circunstâncias similares no futuro. Mais que isso - e esse é o ponto -, todo homem pode ter mais ou menos controle sobre si mesmo pelo modificar de seus próprios hábitos...'(Peirce 1940/1955: 284).

Nossos hábitos podem ser mudados, segundo Peirce, principalmente através de atos de 'imaginação' (Peirce 1940/1955: 284). Mas é evidente que não basta somente imaginação para tal. Precisamos, mais que tudo, querer mudar, diversificar hábitos, imaginar outras possibilidades de afeto, ação e pensamento, o que requer predisposição à tolerancia, flexibilidade e variedade.

E isso só se consegue sendo aberto para o mundo, permitindo a exposição concreta de ideologemas diferente dos nossos habituais por outros sujeitos de outros grupos sociais. Deveríamos não só permitir como incentivar e preservar a prática democrática da significação, que pluraliza meios, canais e opiniões. Pois assim fazendo, nossas próprias possibilidades de significar, de entender a realidade, se multiplicam, nossas opções de vida se enriquecem, e nosso respeito pelo diferente, pelo outro será cada vez maior. Talvez seja essa a herança maior que Peirce, Barthes e Kristeva, entre outros, tenham legado à semiótica, à filosofia e à ciência em geral; pois todos eles começaram pelo estudo da significação e terminaram por reconhecer que a aceitação da diferença do outro é o que mais conta na prática do viver, do conviver. Não devemos simplesmente postular intelectualmente a différance, mas devemos ir além, evitando dicotomias e dualismos. Em outras palavras, vamos explorar as possibilidades de criação e de descobertas que a retórica da comunicação, do diálogo com o outro, nos oferece, ao invés de tentarmos continuamente impor nossas regras e normas, nossa gramática, sobre os demais, como se o mundo devesse sentir, pensar e agir à nossa imagem e semelhança.

Informados pela prática da retórica, do diálogo, da diferença, e animados de um interesse genuíno pelo outro sujeito e pelo seu contexto histórico-social particular, estaremos numa posição sem dúvida muito melhor que a dos cientistas, lógicos e gramáticos formalistas para investigar a comunicação como uma prática de diferença, de mudança, de criação s

\section{Referências}

Cauduro, F V (1996) "Escrita e Différance", Revista FAMECOS n ${ }^{0}$ 5, 63-72, Porto Alegre: EDIPUCRS.

Eco, U (1976) A Theory of Semiotics, Advances in Semiotics, ed. by Thomas A Sebeok, Bloomington: Indiana University Press.

Harland, R (1987) Superstructuralism, New Accents, ed.T Hawkes, London: Methuen.

Peirce, C S (1931) Collected Papers, ed. by Charles Hartshorne and Paul Weiss, vols I - VI, and by Arthur W Burks, vols VII \& VIII, Cambridge: Harvard University Press (Vol I: 1931; vol II: 1932; vol III: 1933; vol IV: 1933; vol V: 1934; vol VI: 1935; vol VII: 1958; vol VIII: 1958).

Peirce, C S (1940/1955) Philosophical Writings of Peirce, selected and edited with an introduction by Justus Buchler, New York: Dover Publications (First published in 1940 as The Philosophy of Peirce: Selected Writings, ed. by Justus Buchler, London: Routledge \& Kegan Paul).

Said, E W (1987) Orientalism, Peregrine Books, London: Penguin Books.

Sless, D (1986a) 'Reading semiotics', in Information Design Journal, 4, no. 3, 179-89.

Sless, D (1986b) In Search of Semiotics, London: Croom Helm.

Urmson, J O, and Rée, J, ed (1989) The Concise Encyclopedia of Western Philosophy and Philosophers, new edition, completely revised, London: Unwin Hyman.

Williams, R (1983) Keywords: A Vocabulary of Culture and Society, London: Fontana. 